\title{
DANÇA EM CADEIRA DE RODAS E PARALISIA CEREBRAL: ESTUDO DE CASO DA MENINA LAURA
}

Fernanda Silva

Bruna Araújo Carvalho

Álvaro Rego Millen Neto

\section{Resumo}

$\mathrm{O}$ estudo analisa as possibilidades da dança com cadeira de rodas enquanto recurso auxiliar para o desenvolvimento dos aspectos afetivo social, cognitivo, psicomotor e terapêutico de uma criança com Paralisia Cerebral. Para tal, foi realizado um estudo de caso de uma menina (Laura) com nove anos de idade. Os dados foram coletados através de entrevistas e um diário de campo. Suas análises permitem as seguintes considerações: o interesse deliberado de Laura, o apoio da família e o acompanhamento de profissionais especializados foram fundamentais para o projeto de dança; sua inclusão em uma escola municipal regular reafirmou as possibilidades da inclusão educacional, desde que se atenda às necessidades didático-metodológicas e estruturais para tal; Laura demonstrou nítida progressão em aspectos motores, tais como subir na cadeira de rodas ou fazer movimentos de dança de forma autônoma; o desenvolver das aulas de dança desencadeou uma notável contribuição em sua auto-estima.

\section{Palavras-Chave}

Paralisia Cerebral; Dança em Cadeiras de Rodas; Inclusão Social.

\section{DANCE WITH WHEELCHAIR AND CEREBRAL PALSY: STUDY OF CASE OF THE LAURA GIRL}

Fernanda Silva

Bruna Araújo Carvalho

Álvaro Rego Millen Neto

\begin{abstract}
The study it analyzes the possibilities of the dance with wheelchair while auxiliary resource for the development of the aspects social affective, cognitive, psychomotor and therapeutical of a child with Cerebral Palsy. For such, a study of case of a girl (Laura) with nine years old was carried through. The data had been collected through interviews and a field daily.

Its analyses allow the following considerations: the deliberate interest of Laura, the support of the family and the accompaniment of specialized professionals had been basic for the dance project; its inclusion in a municipal regular school reaffirmed the possibilities of the educational inclusion, since that if it takes care of to the structural necessities didactic-methodological and for such; Laura demonstrated clear progression in motor aspects, such as to go up in the wheelchair or to make movements of dance of independent form; developing of the dance lessons unchained a notable contribution in its auto-esteem.
\end{abstract}

\section{Key-Words}

Cerebral Palsy; Dance With Wheelchair; Social Inclusion. 


\section{Introdução}

$\mathrm{O}$ artigo aborda as possíveis relações entre um programa de dança com o auxílio de cadeira de rodas e os aspectos afetivo social, cognitivo, psicomotor e terapêutico de uma criança de nove anos com paralisia cerebral. $\mathrm{O}$ interesse pela pesquisa parte da perspectiva atual sobre as pessoas com deficiência. Apesar da crescente conscientização acerca de seus direitos políticos e sociais, acreditamos que ainda há negligência ao acesso a tais direitos, essenciais para o exercício pleno da cidadania. Não raro, crianças deficientes têm seus espaços de sociabilidade circunscritos ao convívio domiciliar e são afastadas das atividades sociais mais amplas. Com relação às academias de ginástica e dança o quadro não é diferente. Grande parte das políticas públicas voltadas para o esporte e o lazer não têm garantido acesso a esse público. Nesse sentido, as atividades motoras adaptadas são aqui entendidas como direito das pessoas com deficiências.

Especificamente com relação à dança para cadeirantes, as possibilidades dela derivadas são amplas. Entendemos que a dança pode contribuir para o enriquecimento das possibilidades artísticas e estéticas, estimular a criatividade e a autonomia, contribuir para a educação corporal, entre outros aspectos. A utilizada como forma de lazer, educação do movimento, terapia e arte. Com essa atividade, pretende-se propiciar aos indivíduos cadeirantes uma melhor qualidade de vida. De outra forma, espera-se que a dança promova melhora na imagem corporal do indivíduo portador de deficiência física, contribuindo para a melhoria da auto-estima, através da valorização das potencialidades individuais.

Diante dessas informações, trabalhamos com a hipótese de que a dança com cadeira de rodas mostra-se eficaz para o desenvolvimento global das pessoas com deficiências. Nesse sentido, as informações coletadas pelo presente artigo, possibilitam, notadamente para a criança elencada para constituir o objeto de estudo, um maior detalhamento das implicações da dança para pessoas com deficiência física. $O$ trabalho também nos possibilitará a verificação das possibilidades de oferecer a uma pessoa com Paralisia Cerebral (PC) tratamento pedagógico com oportunidades e direitos iguais. Pretende-se, dessa forma, mostrar que essas pessoas são diferentes, porém, se não excluídas, podem fazer, dentro de seus limites, diferentes atividades motoras que certamente contribuirão para uma vida mais intensa.

\section{A Paralisia Cerebral}

De acordo com Mattos (2005) a PC é um distúrbio motor não progressivo, com implicações movimentação e na postura. Conseqüência de lesões ou de um mau funcionamento do cérebro, a PC se estabelece antes dos três anos de idade. 
A pessoa com PC tem incapacidade de utilizar alguns músculos do seu corpo de forma normal. Em conseqüência tem dificuldade para andar, falar, comer e realizar tarefas motoras em geral. Por isso se faz importante um tratamento terapêutico para aprimorar os movimentos executados, desenvolvendo movimentos mais precisos e funcionais. Reforçando a importância de tais tratamentos, Moura e Silva (2005, p. 16) afirmam que:

[...] apesar da Paralisia Cerebral ser decorrente de uma lesão não progressiva, o paciente cresce, envelhece, e o desempenho motor funcional tende a piorar com isso. Músculos inicialmente apenas espásticos desenvolvem contraturas, movimentos coreoatetóides vão se tornando diatônicos, a independência em locomover um corpo de 1 metro de altura pode se perder quando esse corpo passa a medir $1,60 \mathrm{~m}$. Essas perdas devem ser levadas em conta quando se planeja inicialmente o tratamento de reabilitação a ser proposto, para que se evitem falsas expectativas e frustrações no decorrer do processo.

Desse modo, o desenvolvimento da motricidade de crianças com PC tem uma dupla importância. Primeiramente em função de se melhorar a qualidade de vida dessas crianças, mas também não se pode desconsiderar a importância de se garantir uma vida adulta mais independente, uma vez que, como indicam os autores, o quadro motor tende a se agravar com o crescimento corporal.

Cada pessoa com PC pode ter um comprometimento diferente, pois as manifestações ocorrem de acordo com a localização das lesões e as áreas do cérebro afetadas. Os distúrbios são classificados em função de fatores que são citados no diagnóstico. Nesse sentido, existem várias classificações fisiológicas, dentre elas citaremos a espasticidade e atetose. Mattos (2005, p. 223-224), assim descreve tais classificações:

Espasticidade - caracterizada por aumento do tônus muscular resultante de lesões no córtex ou nas vias provenientes. Os músculos dos membros são tensos e apresentam reflexo de estiramento. Os indivíduos ficam sujeitos a contraturas e deformidade que se desenvolvem durante o crescimento.

As pessoas com paralisia cerebral espástica têm movimentos desajeitados e rígidos porque seus músculos são muito tensos. Elas têm dificuldades ao modificar sua posição ou ao tentar pegar algo com suas mãos.

Atetose - caracterizada por movimentos involuntários e a variação do tônus muscular resultante de lesões dos núcleos situados no interior dos hemisférios cerebrais (sistema extrapiramidal). O tônus muscular flutua, gerando movimentos involuntários, e os movimentos voluntários se deformam ficando retorcidos. As pessoas com PC atetóide têm dificuldade para se manter nas posições vertical e sentada ou caminhar com segurança e ritmo adequado. Freqüentemente, podemos observar movimentos involuntários na região facial e nos membros superiores. 
De acordo com Hoffmann et al. (2003), quanto ao grau de comprometimento, a PC pode ser classificada como leve, moderada ou grave. Para a PC leve poucos são os comprometimentos físicos e/ou mentais. Essas pessoas têm autonomia nas tarefas motoras e uma considerável adaptação social. Os PC moderados já apresentam dificuldades de locomoção, têm a motricidade fina limitada e necessitam de assistência especial para as tarefas motoras. Já a PC grave incute grande dependência nos aspectos motores e extrema dificuldade na linguagem.

Com relação à representação que se faz acerca da PC, Mattos (2005) alerta para os significados falsos, tais como os de doença contagiosa, anomalia hereditária e, notadamente, portador de deficiência mental. A dificuldade de comunicação, a baixa coordenação motora, os movimentos involuntários, os tônus muscular anormal, entre outras características, são responsáveis por essas representações imprecisas. Nesse sentido, é importante que se destaque que a PC não é uma doença, não é contagiosa e nem evolui.

Em função de suas limitações, por vezes as crianças com PC não se encontram motivadas para experimentar e vivenciar atividades voltadas para seu desenvolvimento motor. Por isso é recomendável que, desde os primeiros meses de vida, o bebê freqüente sessões de terapia motora, mas a oferta de estímulos lúdicos e desafiadores são igualmente fundamentais. Pensando nesses aspectos a serem transpostos, Mattos $(2005,223-224)$ entende que "a qualidade de vida das pessoas com PC pode ser melhorada com a possibilidade de participação em atividades esportivas e competitivas que atendam às suas necessidades e respeitem suas limitações”.

\section{Metodologia}

A pesquisa é de caráter qualitativo, com características etnográficas, configurando-se como um estudo de caso de uma criança de nove anos de idade com PC. Trata-se de uma pesquisa ação, na qual uma das autoras do artigo foi responsável pelas atividades desenvolvidas pelo projeto, realizado em Quatis município localizado na região sul-fluminense.

Os instrumentos de coleta de dados são:

a) entrevistas semi-estruturadas com a família da criança, professores e os profissionais da saúde (psicóloga, fonoaudióloga e fisioterapeuta) que a acompanham desde o nascimento. Nessa etapa metodológica, foi investigado especificamente o histórico dos aspectos cognitivos, afetivo-sociais, psicomotores e terapêuticos; 
b) diário de campo para descrição qualitativa do desenvolvimento do programa de dança. Foram relatados os pontos mais relevantes de cada aula.

\section{Resultados}

\section{Laura em Familia}

Filha de Ana Maria Gonçalves de Almeida e Elias Ribeiro de Almeida, Laura Gonçalves de Almeida nasceu em Quatis, município do sul-fluminense, no dia 24 de março de 1998. Fruto de uma gravidez pósnupcial (foi concebida ainda na primeira semana após o casamento de seus pais), sua gestação foi tranqüila até o oitavo mês. Contudo, ao entrar no nono mês de gestação, sua mãe subitamente ganhou dez quilos, teve sua pressão elevada e ameaça de pré-eclampse. Como conseqüência, ficou internada por uma semana, com dieta controlada, para perder peso e controlar a pressão. Passados quinze dias de sua alta médica, a senhora Ana Maria voltou ao hospital, dessa vez para o nascimento de Laura.

Os exames pré-natais demonstravam uma menina em condições absolutamente perfeitas, foi durante o parto que se desenvolveu o quadro da Paralisia Cerebral. Não houve passagem e nem força para fazer com que Laura nascesse na hora programada. $\mathrm{O}$ adiamento impossibilitou a oxigenação, o que gerou um quadro de hipoxia e, por conseqüência, a Paralisia Cerebral. Laura não chorou e foi levada às pressas para ser entubada e ventilada. Apresentou convulsões em suas primeiras horas de vida, necessitando de medicamento. E seu braço direito foi lesionado em função da força que a equipe médica precisou imprimir durante o parto. Depois de 12 dias Laura recebeu alta, mas com prescrição de medicamentos e fisioterapia.

Com 6 meses de tratamento fisioterápico realizado no hospital de Quatis, voltou o movimento do braço direito. Com um ano de idade, Laura foi matriculada na APAE de Quatis e passou a receber, nessa instituição, tratamento com fisioterapeuta, fonoaudióloga e psicologia. Tratamento esse que permanece até a presente data. Quando completou cinco anos de idade, Laura passou a freqüentar a SARAH-Rio.

Esse tratamento, específico para pessoas com Paralisia Cerebral, teve uma duração de dois anos. Um dos frutos positivos de sua passagem pela SARAH-Rio foi à avaliação pela qual Laura passou, na qual foi submetida a um exame de capacidade intelectual. Sendo aprovada nesse exame, pois apresentava capacidade intelectual dentro do esperado para a média de sua idade, foi emitido um relatório para APAE afirmando que Laura estava apta a ingressar em uma escola de ensino regular. A partir de então, Laura se matriculou em uma escola regular, mas sem deixar de continuar freqüentando a APAE. 
Com relação às suas aulas de dança, sua mãe destaca que Laura veio a ter interesse a partir de um programa de televisão. Mesmo sabendo de suas limitações, ela passou a querer aprender a dançar. Algum tempo depois, em 2007, quando Laura estava com oito anos de idade, surgiu a oportunidade de dançar pela APAE na cidade de Quatis. A mãe de Laura relata que "o sonho de Laura foi realizado"! A família descreve que desde que Laura começou a ter aulas de dança tem ocorrido mudanças em todo o seu sistema motor, o que contribuiu para um melhor equilíbrio nas tarefas cotidianas. No entanto, as aulas de dança não substituem as outras terapias, pois Laura continua acompanhada por diferentes profissionais da área da saúde (fonoaudiólogos, fisioterapeutas, médicos e psicólogos).

Sua mãe afirma que Laura tem sido exemplo para todos e hoje, com 9 anos, seu desenvolvimento nas atividades diárias vem crescendo, o que contribui muito para sua auto-estima.

\section{Laura na Escola}

A professora que esteve com Laura no ano letivo de 2007 cita como sua característica mais marcante, a determinação. Na escola que a recebeu não havia nenhum outro caso de inclusão de pessoas com necessidades especiais, Laura foi a primeira que essa instituição ensino atendeu. Foi matriculada no Pré II, pois a escola observou alguns pré-requisitos necessários à alfabetização, que não haviam sido trabalhados na APAE.

Antes de receber Laura houve um trabalho de conscientização e sensibilização com a utilização de um boneco especial, batizado pelos alunos como Marcelo, que não se locomovia sozinho e necessitava de cuidados especiais. Marcelo visitou a casa de cada aluno durante um determinado tempo e, ao retornar com Marcelo para a escola, o aluno que o havia acolhido contava para a turma como foram os dias em sua companhia. Desta forma, Marcelo foi incluído ao grupo que aprendeu a brincar e se relacionar com Laura com a devida atenção e os cuidados de que ela necessita e merece.

Quanto ao desenvolvimento de Laura nas atividades propostas, sua ex-professora relata que ela é uma criança que participativa das atividades e se mostra sempre interessada. Um aspecto relevante apontado pela ex-professora é que Laura se relaciona muito bem com outras crianças. Em resposta a uma de nossas indagações, foi interessante a informação dada pela professora, descrevendo Laura como uma aluna que está sempre atenta, possui personalidade e senso crítico. 
Há um comprometimento com os aspectos psicomotores e, por isso, sua letra não é muito legível e tem um tamanho exagerado. Ela também necessita de ajuda ao utilizar a tesoura. E, apesar das dificuldades com a fala, isto não a impede de se expressar oralmente. Para concluir, a professora destaca a força de vontade de Laura de estar sempre querendo aprender.

Quando foi iniciada nas aulas de dança, pode-se perceber o reflexo dessa atividade na escola. A motivação demonstrada por Laura durante as conversas em sala de aula expressou nitidamente o quanto as aulas de dança estavam contribuindo para sua auto-estima.

\section{Laura na Psicóloga}

Sua psicóloga esclareceu que atende Laura desde março de 2000, com sessões de 30 minutos nas quais são trabalhadas as metas terapêuticas traçadas. Diante da deficiência e suas conseqüências para as questões afetivo-sociais, essa profissional procura relatar os pontos mais relevantes sobre a criança Laura. Uma das primeiras metas do plano terapêutico traçado pela psicóloga, para o tratamento de Laura, foi trabalhar a ansiedade tanto com a paciente quanto com a família. Seu tratamento também tem o objetivo de avaliar as possibilidades cognitivas, a auto-estima e estimular as estruturas egoísticas.

Quando perguntamos a respeito das possíveis contribuições que a dança exerce sobre o tratamento psicológico de Laura, a psicóloga citou a elevação da auto-estima. Essa profissional nos relatou que Laura passou a ser uma criança mais descontraída, alegre e feliz. E, quando a palavra dança é citada em suas sessões de terapia, percebe-se uma luz nos olhos de Laura e um sorriso aberto.

\section{Laura na Fonoaudióloga}

O acompanhamento com a atual fonoaudióloga se iniciou em 2003, mas Laura já era assistida anteriormente na entidade. Referente ao quadro encontrado nós perguntamos como Laura estava quando começou o seu primeiro atendimento. Sua fonoaudióloga afirma que Laura chegou com cognitivo e linguagem preservados, se comunicava verbalmente, sendo lenta sua fala, laboriosa e sem inflexão. Laura apresenta dislalia (ou seja, trocas e omissões fonêmicas), sua mordida é aberta e sua respiração é bucal. Uma característica de sua deficiência.

Com o trabalho que vem sendo realizado na fonoterapia, a estimulação do tônus muscular de lábios e língua, o ritmo e a entonação da fala, a instalação do ponto articulatório dos fonemas e sua automatização 
e as habilidades motoras, juntamente com os profissionais de psicologia e fisioterapia, a determinação e dedicação da paciente Laura, têm contribuído para obter resultados positivos. A fonoaudióloga afirma que sabe que as respostas são a longo prazo, porém existe uma melhora significativa na sua articulação e a instalação de alguns fonemas, e completa: "ainda há muito trabalho"!

A partir das aulas de dança nós perguntamos se ela percebeu alguma modificação que refletiu no seu trabalho. Ela esclarece que a dança foi um fator decisivo que veio somar ao trabalho desenvolvido no setor clínico. As atividades práticas amadureceram e elevou a auto-estima. Laura se sente mais útil e mais importante por estar aprendendo e vivenciando algo novo. Superando, cada vez mais, as suas limitações. Assim, foi aumentando ainda mais as características marcantes de Laura, que são: a persistência, a determinação, a dedicação e a superação.

\section{Laura na Fisioterapia}

Laura recebe tratamento do fisioterapeuta que contribuiu com a pesquisa desde 2001. De acordo com esse profissional, seu quadro inicial era insatisfatório, Laura não sentava ativamente, não rolava, ou seja, não fazia mudanças de decúbitos, não controlava o tronco nem a cabeça ativamente, e tão pouco engatinhava. As principais atividades terapêuticas realizadas são: atividades para controle da exacerbação do tônus, alongamento para psicomotricidade e quadro motor global. A maior dificuldade psicomotora é quanto à exacerbação do tônus (atetose).

Após esses anos de tratamento, Laura teve considerável evolução em seu quadro psicomotor. Atualmente, conforme o fisioterapeuta, ela é de uma paciente que faz ativamente todas as mudanças de decúbitos, controla o tronco e a cabeça, engatinha e deambula (anda) passivamente, e só não o faz ativamente em função da atetose.

Com relação às aulas de dança, seu fisioterapeuta considera que tal atividade tem motivado a paciente e ajudado a quebrar barreiras quanto à sua capacidade física, desfazendo a monotonia das sessões de fisioterapia que o tratamento requer. Ele acrescenta que a dança é uma expectativa esperada por Laura desde quando foi iniciado o tratamento, isto é, um sonho realizado. Com isso o quadro psicomotor sem dúvida teve progresso. 


\section{Laura na Dança ${ }^{1}$}

Através de um trabalho voluntário com crianças deficientes mentais na APAE de Quatis, iniciado no ano de 2006, conheci a paciente Laura. Nessa instituição ela não é aluna, realiza somente tratamento de fisioterapia, fonoaudióloga e psicóloga. Com sua simpatia e sempre disposta a encarar algo novo, um dos sonhos de Laura era ser dançarina. E, mesmo com a sua limitação causada pela paralisia cerebral, e sendo cadeirante, nunca pensou que um dia não poderia realizá-lo.

A proposta das aulas de dança veio através de um convite feito pela própria diretora dessa instituição. A princípio, confesso que senti medo de encarar o que para mim era novo, sabia que seria uma grande aprendizagem para ambas as partes. Tive medo de não alcançar resultados satisfatórios e gerar uma frustração em função de suas limitações.

No final do ano de 2006, na abertura dos Jogos da Superação, evento envolvendo pessoas com necessidades especiais realizado no município fluminense de Cabo Frio, assisti a uma apresentação de dança de uma criança com paralisia cerebral e me emocionei muito. Pensava somente na Laura e que a realização do seu sonho dependia da minha força de vontade e da quebra de barreiras. Voltei decidida e ansiosa para encarar o desafio.

Laura ainda não sabia da proposta que eu havia recebido. Antes de começar o programa das aulas de dança, freqüentei por dois meses suas sessões de fisioterapia para conhecer melhor sua deficiência e suas características. E, meu primeiro contato com a Laura na fisioterapia foi para dar a notícia das aulas de dança. Ela ficou radiante e emocionada. Nas sessões que se seguiram, tive a oportunidade de manuseá-la, tirando e colocando-a da cadeira de rodas, conhecendo mais suas limitações e estabelecendo o contato corporal. Assim, através desse trabalho com a ajuda do fisioterapeuta, e conhecendo melhor a deficiência da Laura, causada pela paralisia cerebral, comecei o programa das aulas de dança.

O programa teve início em março de 2007 e é realizado na própria instituição, toda sexta-feira de $13 \mathrm{~h} 30 \mathrm{~min}$ às $15 \mathrm{~h}$. Nossa primeira aula foi muito esperada, Laura chegou bastante ansiosa e com muita vontade de experimentar. Apresentei a nossa primeira música de trabalho e, durante a montagem da coreografia, ela demonstrou muita alegria. Chegou a dizer que eu estava realizando o sonho dela de ser dançarina.

\footnotetext{
${ }^{1}$ Enquanto protagonista do trabalho com dança em cadeira de rodas, realizado com a menina Laura, uma das autoras do presente artigo foi a responsável pela descrição que se segue. Por isso o tom na primeira pessoa.
} 
Durante os ensaios seguintes, num determinado passo da coreografia em cima da cadeira de rodas, Laura me pediu para trocar de mão dizendo que queria realizar o movimento com a mão direita, justamente a que tem um comprometimento mais acentuado, causando-lhe maiores dificuldades motoras. Essa atitude demonstrou sua consciência sobre as possibilidades terapêuticas que a dança pode lhe oferecer. Acredita que trabalhando mais com a mão direita, pode diminuir essa dificuldade. Ela tem demonstrado muita força de vontade em querer aprender e tentar se aperfeiçoar, com isso tem elevado sua auto-estima.

Nossa primeira apresentação foi nos Jogos Especiais de Quatis e foi esperada por todos (família, amigos e professores) e principalmente por nós duas. Laura não escondia o seu nervosismo e sua ansiedade e chegou a dizer que queria mostrar para todos que ali estavam que, mesmo com a sua deficiência, ela poderia dançar e fazer muito sucesso para Deus. Realizamos várias outras apresentações com a primeira música de trabalho: na praça (evento Música no Parque), na sua própria escola, no encerramento dos jogos estudantis de Porto Real e no festival de dança do UBM (Centro Universitário de Barra Mansa).

Durante os ensaios para o festival de dança do UBM, Laura dizia estar muito nervosa, pois estava prestes a se apresentar para um público maior e queria fazer bonito. A felicidade e a alegria estavam transparentes em seu rosto. Pediu para trocar o passo final da coreografia porque suas pernas estavam sem controle e sugeriu outro passo que foi adaptado em função de sua limitação. No final da aula, em uma conversa informal, disse que já estava conseguindo subir na cama depois que começou fazer aula de dança.

Com a segunda música de trabalho realizamos outras apresentações: nos Jogos Especiais de Porto Real, na igreja, na festa da APAE de Quatis e em Volta Redonda, no Ginásio Raulino de Oliveira, durante a apresentação de um trabalho falando sobre paralisia cerebral.

Depois das férias de Julho e com um mês sem aula de dança, Laura chegou dizendo que estava sentindo falta de dançar e estava muito entusiasmada e curiosa para saber a próxima música de trabalho. Achou linda a nova música, deu várias sugestões para o figurino e com a sua criatividade contribuiu muito para a montagem da coreografia. Com o passar das aulas, Laura tem usado sua capacidade criadora, sua imaginação e sua autocrítica, buscando sempre se aperfeiçoar dentro de suas limitações. 
Com relação ao aspecto afetivo social, em uma aula de dança, Laura chegou triste dizendo que seus pais estavam brigados e que não gostava de vê-los assim. Antes de iniciar a aula tivemos uma conversa muito proveitosa e, com o passar das horas, foi melhorando seu estado emocional e a aula foi ficando alegre e com muitos risos. Laura está mais confiante e está perdendo o medo de subir na cadeira de rodas. Assim, com o passar dos meses, vem demonstrando empenho em tudo que é proposto. As aulas estão se tornando mais proveitosas e com um rendimento melhor.

Nossa terceira música de trabalho foi apresentada nos Jogos Especiais de Itatiaia e na $1^{\circ}$ Mostra de Dança de Quatis. Enfim, com a sua determinação e auto-confiança, Laura tem demonstrado dedicação e persistência superando os obstáculos encontrados através de sua deficiência.

\section{Considerações Finais}

Este trabalho teve como escopo a análise das possibilidades da dança com cadeira de rodas enquanto recurso auxiliar para o desenvolvimento dos aspectos afetivo social, cognitivo, psicomotor e terapêutico de uma criança com Paralisia Cerebral. A partir da experiência realizada com a menina Laura, podemos afirmar que o primeiro passo para um projeto com pessoas especiais é a auto-aceitação. O deficiente deve se aceitar, de modo que o interesse venha de sua parte para a realização das atividades. Nesse sentido, os sonhos e planos da menina Laura de se tornar uma bailarina em muito favoreceram para o sucesso de suas aulas de dança e a conseqüente repercussão positiva em outras esferas de sua vida.

Outro fator indispensável é o apoio da família e o acompanhamento de profissionais especializados. Para o estudo de caso que norteou a presente pesquisa, ficou claro que estas foram premissas fundamentais para que o projeto de dança oferecesse um retorno mais contundente, possibilitando reflexos positivos para os outros profissionais que atendem a menina Laura, tais como a professora da escola regular, a psicóloga, a fonoaudióloga, o médico e o fisioterapeuta. Assim, como mais um aporte resultante da pesquisa, fica a indicação da necessidade de se realizar projetos transdisciplinares, envolvendo as diferentes áreas responsáveis pelo desenvolvimento de uma criança com Paralisia Cerebral.

Para promover a inclusão, entendemos que a escola precisa assumir uma atitude de mudanças gerais sobre as práticas educacionais. As adaptações precisam ocorrer em todas as partes e os sistemas educacionais precisam se adequar para melhor atender às pessoas especiais. A inclusão da menina Laura em uma escola regular da rede municipal de ensino reafirmou que a utopia da inclusão educacional é 
possível, desde que se atenda às necessidades didático-metodológicas e estruturais para tal e que haja um trabalho de conscientização e de sensibilização para que a comunidade escolar saiba lidar com o aluno especial. Nesse sentido, a dinâmica realizada com o boneco Marcus foi louvável.

Também entendemos que a Paralisia Cerebral, enquanto distúrbio da motricidade que afeta o desenvolvimento da criança, não impede a realização de atividades motoras, respeitando as limitações de cada paralisado cerebral. Percebemos que, com a diagnose e os estímulos adequados, a criança estará apta para desenvolver atividades como a dança em cadeira de rodas. Outrossim, a atividade física para a criança com esta característica estimula o desempenho motor que futuramente poderá estar mais comprometido - em função do crescimento corporal.

A dança para crianças com Paralisia Cerebral se mostrou uma terapia e um excelente estímulo para a experimentação sensorial, o ritmo, o equilíbrio, a coordenação, o desenvolvimento motor e a socialização. Reafirmando o que Maria Amália Giffoni (1964) já destacava, ficou explícito no desenvolver do trabalho que a dança contribuiu para aprimorar não somente os aspectos físicos, mas notadamente os atributos sociais, culturais e cognitivos do ser humano de maneira integral. Além de estimular o raciocínio, a atenção e a memória, foi capaz de revelar o valor individual para criar, usar a imaginação e revelar o seu lado artístico. Como prova de tal assertiva, a menina Laura demonstrou progressão em diversos aspectos: além dos motores, como subir na cadeira de rodas, na cama ou fazer movimentos de dança de forma autônoma, se mostrou uma aluna crítica e autocrítica e, progressivamente, se envolveu até mesmo na construção das coreografias que a princípio eram tarefa exclusiva da professora.

Por fim, o dia a dia da investigação participativa possibilitou a percepção de que o desenvolver das aulas de dança desencadeou uma notável contribuição para a auto-estima da menina Laura, como no dia em chegou para a aula contrariada e da lá saiu feliz e confiante. Fato que, por si só, justificaria um projeto como esse e que muito nos alegra por estarmos aqui o relatando. 


\section{Referências}

GIFFONI, M. A. C. Danças folclóricas brasileiras. 2. ed. São Paulo: Melhoramentos, 1964.

HOFFMANN, R. A.; TAFNER, M. A.; FISCHER, J. Paralisia Cerebral e Aprendizagem: Um estudo de caso inserido no ensino regular. Revista Leonardo Pós: Instituto Catarinense de Pós Graduação, v. 2, jan.- jun. 2003.

MATTOS, E. Atividade física nos distúrbios neurológicos e musculares. In: GORGATTI, M. G.; COSTA, R. F. (Orgs.). Atividade física adaptada: qualidade de vida para pessoas com necessidades especiais. São Paulo: Manole, 2005.

MOURA, E. W.; SILVA, P. A. Fisioterapia: aspectos clínicos e práticos da reabilitação. São Paulo: Artes Médicas 1tda, 2005. 


\title{
Fernanda Silva
}

Licenciada em Educação Física pelo Centro Universitário de Barra Mansa

Professora da APAE do Município de Quatis

e-mail fernandinha.edfisica@hotmail.com

\section{Bruna Araújo Carvalho}

Licenciada em Educação Física pelo Centro Universitário de Barra Mansa

\author{
Álvaro Rego Millen Neto \\ Mestre em Educação Física pela Universidade Gama Filho \\ Professor da Universidade Federal do Rio de Janeiro \\ Professor do Centro Universitário de Barra Mansa \\ Bolsista de Apoio Técnico a Pesquisa - CNPq \\ e-mail amillen@gmail.com
}

